Check for updates

1 Department of mathematics, University College London

2 Department of chemistry, University of Bath

Cite this as: $B M J 2021 ; 375: n 3149$ http://dx.doi.org/10.1136/bmj.n3149 Published: 23 December 2021

\title{
Schools: still a gaping hole in the English covid strategy
}

\section{Christina Pagel, ${ }^{1}$ Adam Squires ${ }^{2}$}

In August, one of us (CP) wrote about schools being the gaping hole in the English covid strategy. This was written in the face of the highly transmissible delta covid-19 variant. ${ }^{1}$ Three failings were identified: delayed vaccination of 12-15 year olds; lack of public health measures in schools such as masks and ventilation; and continued high community transmission leaving schools vulnerable. So what happened? And what needs to happen next?

\section{What happened}

Vaccines were finally rolled out to 12-15 year olds towards the end of September, three weeks into the start of term. ${ }^{2}$ Unlike the roll out in Scotland, vaccines were initially offered in school settings and progress was slow. As of 19 December, only $47 \%$ of $12-15$ year olds have received one dose. ${ }^{3}$ Meanwhile, the US Food and Drugs Administration (FDA) approved vaccines for 5-11 year olds at the end of October and the European Medicines Agency did so a month later. ${ }^{45}$ The UK Medicines and Healthcare products Regulatory Agency (MHRA) and Joint Committee on Vaccination and Immunisation (JCVI) have yet to make a decision, but recent indications are that JCVI will only recommend vaccination for clinically extremely vulnerable 5-11 year olds. ${ }^{6}$

Schools have navigated this term with essentially no nationally required mitigation measures except for isolation for children who test positive. Carbon dioxide ( $\left.\mathrm{CO}_{2}\right)$ monitors were promised to all schools in September, but most had still not been delivered by November. ${ }^{7}$ HEPA filters and germicidal ultraviolet light to reduce airborne transmission are being trialled in schools in Bradford, but have not been not rolled out more generally. ${ }^{8}$ Community transmission rates have remained high all autumn: 32 ooo cases have been reported daily on average in England since 1 September.

The consequence has been very high rates of infection in children. Over one million children under 16 years have had a confirmed infection since 1 September 2021, more than the rest of the pandemic combined. ${ }^{9}$ Rates in 5-19 year olds have been the highest across all age groups since September. The Office of National Statistics Infection Survey has reported the highest prevalence in primary and secondary school children since the start of the pandemic (in two October weeks almost $10 \%$ of secondary school children tested positive each week). ${ }^{10}$ Prevalence has been consistently more than three times as high as adults. As more teenagers became vaccinated over the autumn, primary school children saw the highest infections among all age groups for the first time in the pandemic.10 Schools suffered a lot of disruption as students and teachers fell sick. ${ }^{11}$ Over 2,00o 6-17 year olds have been admitted to hospital with covid-19 since 1 September and 10 5-14 year olds have died with covid as contributing cause, compared to 720 and two respectively over the same period in 2020. ${ }^{12}{ }^{13}$ Children are reporting rising cases of long covid too-a trend only likely to get worse as data come in from the last few months of the year. ${ }^{14}$

High cases in children have also spilled over into their parents' generation- cases in 35-49 year olds have consistently been the highest among adults and have risen and fallen together with cases in school age childre. ${ }^{10}$

\section{The omicron spanner in the works}

The omicron variant is now dominant in England. It is both highly transmissible and immune evasive. ${ }^{15}$ It has been doubling every two days in England and has resulted in record cases over recent days-far higher than last January's peak. ${ }^{1617}$ Previous infection or two vaccine doses do not provide much protection from infection with omicron. ${ }^{18}$ While three doses of vaccines are required to provide significant protection from omicron infection, any dose is expected to provide at least some protection from severe outcomes. ${ }^{19}$ Chris Whitty, England's chief medical officer, and Jenny Harries, head of the UK Health Security Agency (UKHSA) have both warned of a substantial new wave of infections over the coming weeks. As of 19 December, almost 40\% of 16-17 year olds and over $50 \%$ of $12-15$ year olds remain unvaccinated. ${ }^{3}$ Under 12 s remain unvaccinated. As the new term starts in January therefore, children are the population at highest risk of a large new wave of infection, this time driven by omicron and not delta.

\section{What needs to happen next \\ Vaccines}

Over seven million doses have been administered to 5-11 year olds in the USA. So far, there have been only eight reports of myocarditis, all mild.20 Many European countries have now started vaccinating primary school age children since EMA approval in November. ${ }^{20}$ We had given a first dose to $50 \%$ of 16 and 17 year olds by end of September 2021 and this age group did not see a large spike in the autumn term. ${ }^{321}$ We had given a first dose to a third of 12-15 year olds by early November and by December case rates were higher in primary school children than secondary school children for the first time in the pandemic. ${ }^{310}$ Vaccines are safe and they work. By reducing the chance of primary infection, vaccines reduce cases, transmission, long covid, and school disruption. They also protect children from becoming severely ill. With omicron the dominant variant for next term, we cannot rely on previous infection to prevent a new wave of infections in schools. We must offer as many teenagers as possible their second dose before term starts. The Joint Committee on Vaccinations and Immunisation (JCVI) are reported to have decided that only clinically vulnerable 
children should be offered the vaccine. ${ }^{5}$ With the most recent ONS infection survey reporting almost $6 \%$ prevalence in under $12 \mathrm{~s}$ and over $3 \%$ of primary school children off with covid at the end of December, we urge the JCVI to reconsider. ${ }^{1022}$

\section{Clean air}

We can lower covid transmission using methods that work against other airborne pathogens; they are all carried on respiratory aerosol particles released into the room by breathing and talking, and disease spreading is contained by cleaning these particles from the air. ${ }^{23}$ There are different ways to achieve this; some are quick, inexpensive improvements to current classrooms, and some require longer term investment. As each covid variant is more transmissible than the last, clean air becomes an ever more important-and long lasting-defence.

We need more $\mathrm{CO}_{2}$ monitors. Most UK classrooms rely on natural ventilation through windows or doors. ${ }^{24}$ The ventilation delivered depends on the weather and is hard to guess, but teachers need to manage window opening in real time to stop too much exhaled air building up, while keeping the classroom at a reasonable temperature. Having a visible $\mathrm{CO}_{2}$ display in the room helps achieve this. ${ }^{25}$ We therefore recommend a $\mathrm{CO} 2$ monitor for every naturally ventilated classroom, rather than the current one to two shared across a school.

Further adjustments can be made to provide cleaner air. Windows bolted shut could be opened with restrictors for safety; and ventilation can be enhanced using fans placed by windows. ${ }^{26}$ Where ventilation is still insufficient, HEPA units can provide clean air by filtering out the infectious respiratory particles. The technology was shown to be effective against covid in hospitals, and many low-cost home "air purifiers" have the required H13 filter standard and can deliver enough clean air with several units per classroom. ${ }^{27}$ With guidance on sources and numbers required, schools can quickly take advantage of these, rather than being limited by the two models currently recommended by the government. ${ }^{28}$ In the longer term, infrastructure upgrades combining clean air with energy efficiency represent a good investment for the future.

\section{Other public health protections}

Finally, while vaccination and clean air are the foundations of safer schools, there are many other protections we can implement-and which are increasingly important given omicron's high transmissibility. Masks need to be worn inside and outside of classrooms wherever possible by both students and staff, preferably high quality FFP2 masks that could be provided (with funding support) by schools at the entrance. With the higher risk of transmission from the omicron variant to household members of an index case, children who have a household member with covid should isolate for 10 days and be supported to learn remotely, otherwise chains of transmission are just prolonged. ${ }^{29}$ We also need better surveillance testing. Lateral flow tests have been an important intervention, but they are unpleasant, easy to do badly and too many students do not do them at all. There are more efficient ways to monitor large scale settings such as schools. Pooled testing using saliva based swabs have been found to be very effective in the United States and Germany, and has been successfully implemented, for instance in Massachusetts. ${ }^{30-32}$

Last term we failed our children-schools, in combination with the delta variant, became a vehicle for infecting hundreds of thousands of children, and then, their parents. The same gaps in school policy identified in August remain today and are now even more important in the face of a new omicron wave in schools in January. Children are the least protected group in England and their needs are being forgotten as we race to boost adults. Another term of infection and disruption would be a dereliction of duty.

Competing interests: CP is a member of Independent SAGE. AS is Bath University lead for the EPSRC Centre for Doctoral Training in Aerosol Science

Provenance and peer review: not commissioned, not peer reviewed.

Christina Pagel. Schools-a gaping hole in the English covid strategy. The BMJ. 2021. https://blogs.bmj.com/bmj/2021/08/20/christina-pagel-schools-a-gaping-hole-in-the-englishcovid-strategy/

NHS England. NHS rolls out COVID-19 jab to children aged 12 to 15 . https://www.england.nhs.uk/2021/09/nhs-rolls-out-covid-19-jab-to-children-aged-12-to-15/

Vaccinations in England / Coronavirus in the UK. https://coronavirus.data.gov.uk/details/vaccinations?areaType=nation\&areaName=England

4 Commissioner 0 of the. FDA Authorizes Pfizer-BioNTech COVID-19 Vaccine for Emergency Use in Children 5 through 11 Years of Age. FDA. 2021. https://www.fda.gov/news-events/press-announcements/fda-authorizes-pfizer-biontech-covid-19-vaccine-emergency-use-children-5-through11-years-age

BERBECE C. Comirnaty COVID-19 vaccine: EMA recommends approval for children aged 5 to 11 European Medicines Agency. 2021. https://www.ema.europa.eu/en/news/comirnaty-covid-19vaccine-ema-recommends-approval-children-aged-5-11.

6 Stewart $\mathrm{H}$, Walker $\mathrm{P}$. JCVI set to recommend vaccinating only vulnerable five- to 11-year-olds. The Guardian. 2021. https://www.theguardian.com/society/2021/dec/22/jcvi-set-to-recommend vaccinating-vulnerable-five-to-11-year-olds

7 COVID-19. Majority of CO2 monitors not yet delivered to schools as coronavirus-related absences rise. Sky News. https://news.sky.com/story/covid-19-majority-of-co2-monitors-not-yet-deliveredto-schools-as-coronavirus-related-absences-rise-12460709

8 Covid: Air purifier and UV light pilot to combat school virus spread. BBC News. 2021 https://www.bbc.com/news/uk-england-leeds-58190189.

9 New cases by age in England - Government daily Covid-19 dashboard. 2021. https://api.coronavirus.data.gov.uk/v2/data?areaType=nation\&areaCode=E92000001\&metric=newCasesBySpec imenDateAgeDemographics\&format=csv

10 Coronavirus (COVID-19) Infection Survey, UK Statistical bulletins - Office for National Statistics. https://www.ons.gov.uk/peoplepopulationandcommunity/healthandsocialcare/conditionsanddiseases/bulletins/coronaviruscovid19infectionsurveypilot/previousReleases

11 Weale S, Davis N. English schools struggle to cope as Covid wreaks havoc. The Guardian. 2021 https://www.theguardian.com/world/2021/oct/22/english-schools-struggling-to-cope-as-covid wreaks-havoc

12 Download data / Coronavirus in the UK. https://coronavirus.data.gov.uk/details/download

13 Deaths registered weekly in England and Wales by age and sex - Office for National Statistics. https:/www.ons.gov.uk/datasets/weekly-deaths-age-sex/editions/covid-19/versions/4

14 Prevalence of ongoing symptoms following coronavirus (COVID-19) infection in the UK - Office for National Statistics. https://www.ons.gov.uk/peoplepopulationandcommunity/healthandsocialcare/conditionsanddiseases/bulletins/prevalenceofongoingsymptomsfollowingcoronaviruscovid19infectionintheuk/2december2021

1515 December 2021 Risk assessment for SARS-CoV-2 variant: Omicron VOC-21NOV-01 (B.1.1.529)

16 Omicron daily overview: 21 December 2021.

17 Daily Covid-19 cases in the UK exceed 100000 for first time. BBC News. 2021 https://www.bbc.com/news/uk-59758757

18 Omicron largely evades immunity from past infection or two vaccine doses | Imperial News | Imperial College London. Imperial News. https://www.imperial.ac.uk/news/232698/omicronlargely-evades-immunity-from-past/

19 Andrews N, Stowe J, Kirsebom F, et al. Effectiveness of COVID-19 vaccines against the Omicron (B.1.1.529) variant of concern.

20 European Union starts drive to vaccinate children against COVID | Reuters. https://www.reuters.com/business/healthcare-pharmaceuticals/european-union-starts-drivevaccinate-children-against-covid-2021-12-15/

21 Weekly_COVID-19_and_Influenza_Surveillance_Graphs_W50.pdf. https://assets.publishing.service.gov.uk/government/uploads/system/uploads/attachment_data/file/1041446/Weekly_COVID19_and_Influenza_Surveillance_Graphs_W50.pdf

22 Attendance in education and early years settings during the coronavirus (COVID-19) pandemic, Week 50 2021. https://explore-education-statistics.service.gov.uk/find-statistics/attendance-ineducation-and-early-years-settings-during-the-coronavirus-covid-19-outbreak

23 Tellier R, Li Y, Cowling BJ, Tang JW. Recognition of aerosol transmission of infectious agents: a commentary. BMC Infect Dis 2019;19:101. doi: 10.1186/s12879-019-3707-y. pmid: 30704406

24 Korsavi SS, Montazami A, Mumovic D. Ventilation rates in naturally ventilated primary schools in the UK; Contextual, Occupant and Building-related (COB) factors. Build Environ 2020;181:107061. doi: 10.1016/j.buildenv.2020.107061.

25 Di Gilio A, Palmisani J, Pulimeno M, etal. CO2 concentration monitoring inside educational buildings as a strategic tool to reduce the risk of Sars-CoV-2 airborne transmission. Environ Res 2021;202:111560. doi: 10.1016/j.envres.2021.111560. pmid: 34224708 
26 Savage M, Packham A. England's schools in urgent need of repairs, say heads. The Observer. 2021.https://www.theguardian.com/education/2021/aug/28/england-schools-in-urgent-need-ofrepairs-say-heads

27 Conway-Morris A, Sharrocks K, Bousfield R, etal. The removal of airborne SARS-CoV-2 and other microbial bioaerosols by air filtration on COVID-19 surge units.2021.

doi: 10.1101/2021.09.16.21263684

28 The trouble with DfE-approved air purifiers. Tes Magazine. https://www.tes.com/magazine/news/general/heads-shock-over-expensive-dfe-air-purifiers

29 SARS-CoV-2 variants of concern and variants under investigation.

30 Joachim A, Dewald F, Suárez I, etalB-FAST study group. Pooled RT-qPCR testing for SARS-CoV-2 surveillance in schools - a cluster randomised trial. EClinicalMedicine 2021;39:101082 doi: 10.1016/j.eclinm.2021.101082. pmid: 34458708

31 Mendoza RP, Bi C, Cheng H-T, etal. Implementation of a pooled surveillance testing program for asymptomatic SARS-CoV-2 infections in K-12 schools and universities. EClinicalMedicine 2021;38:101028. doi: 10.1016/j.eclinm.2021.101028. pmid: 34308321

32 Coronavirus/COVID-19. COVID-19 Testing Program. https://www.doe.mass.edu/covid19/testing/

33 Reuters. Eight heart inflammation cases among young kids who got COVID-19 shot - U.S. CDC. Reuters. 2021. https://www.reuters.com/world/us/eight-heart-inflammation-cases-seen-amongyoung-kids-who-got-covid-19-shot-us-2021-12-16/ 